\title{
The Construction Of A Business Model For Intellectually Disabled Workers
}

Haruyo Wada, Social Welfare Organization Shouyuhkai, Japan Kenji Ishikawa, Social Welfare Organization Shouyuhkai, Japan Mitsuharu Ohta, Social Welfare Organization Shouyuhkai, Japan Miwa Kojima, Social Welfare Organization Shouyuhkai, Japan Motoki Saito, Social Welfare Organization Shouyuhkai, Japan Kanako Baba, Social Welfare Organization Shouyuhkai, Japan Hiroko Mikame, Social Welfare Organization Shouyuhkai, Japan

\begin{abstract}
The Japanese welfare system has undergone rapid change. A law has been enacted that requires the handicapped to work in order to be independent from government assistance. However, it is difficult for the intellectually disabled (ID) to earn a living wage because of a lack of understanding with respect to their ability and communication skills. Our organization conducts business with ID individuals such as those with autism. The business model for the income of our organization and the ID individuals concerned was successfully constructed through an understanding and application of the characteristics of ID individuals. This paper shows the current environment affecting the ID and presents our strategic and successful business model that is designed to enable them to achieve a realistic livelihood.
\end{abstract}

Keywords: Social Welfare Business; Business Model; The Intellectually Disabled Workers; Vocational Training

\section{BACKGROUND}

\section{1-1. The Japanese Welfare System For The ID}

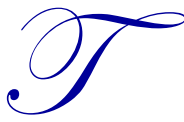

he Japanese handicapped are categorized by three groups according to social welfare law: namely, the physically disabled, the mentally retarded, and those diagnosed with mental disorders. The mentally retarded are generally referred to as the intellectually disabled (ID). Intellectual disability is defined as "characterized by significant limitations both in intellectual functioning and adaptive behavior as expressed in conceptual, social, and practical adaptive skills" (the American Association on Intellectual and Developmental Disabilities, 2010, p.5). The term ID is generic, and the specific disabilities include autism, learning disabilities, asperger syndrome, and attention deficit hyperactivity disorder.

To receive social welfare services and support in Japan, the ID must obtain mental disability certification. First, the individual is measured by the examination and the level of disability is assessed according to four levels. Next, the type of services and support available to an individual were determined by the level of disability.

The services and support are composed of daytime activities and housing support services. The daytime activities are categorized into three types. The first category is composed of long-term care benefits that include medical and welfare type life care. For example, the services provided include meals and personal hygiene care. The second category is community life support services, which supports involvement in local activities such as sports and arts. The third category is rehabilitation benefits, which includes vocational training and training to improve social abilities and techniques. This service is additional since the passing of a new social welfare law in 2012. This service was added in an attempt to decrease the social welfare budget. The ID population has been increasing as has the welfare budget and the effects on the national economy. 
According to the Ministry of Health, Labor, and Welfare (2012) survey, Figure 1 shows that the ID population was 329,200 in 2000 and increased to 547,000 in 2005 . This is an increase of $12 \%$ in five years.

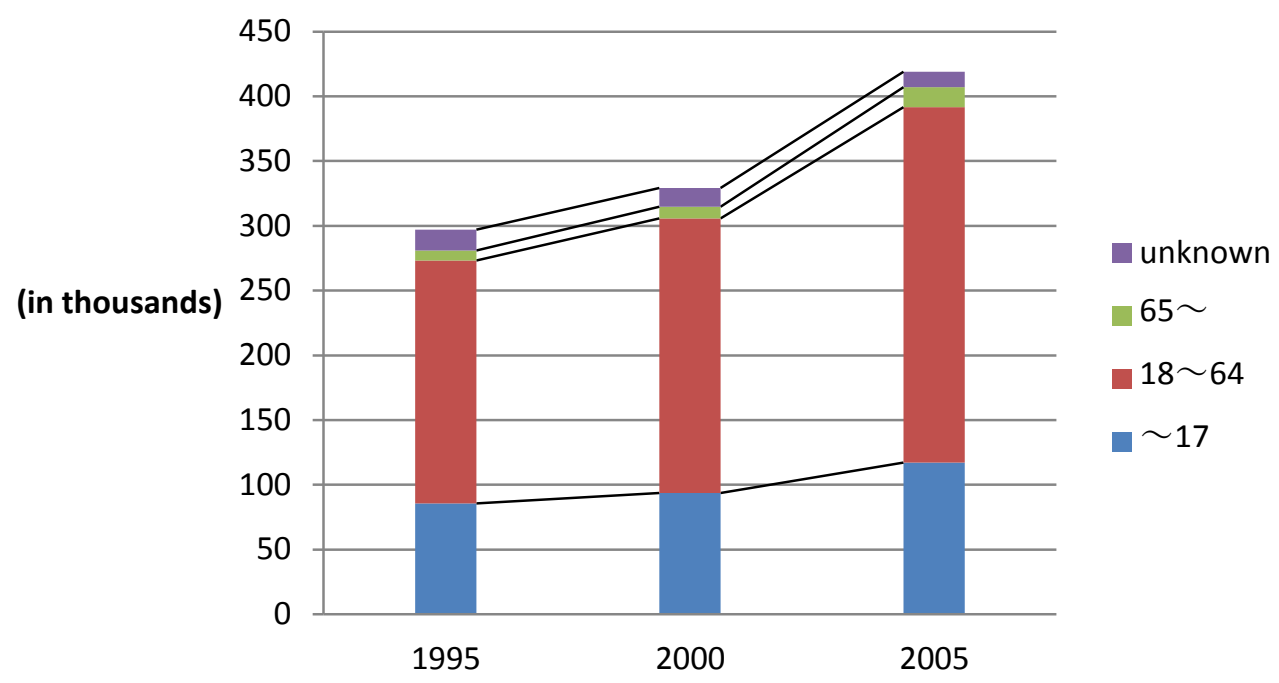

Data: Statistical Bureau, Ministry of Health, Labor, and Welfare (2012): The ID people Statistics

Figure 1: Trends In ID Numbers Classified By Age Group

Figure 2 presents the trends in social welfare expenses since 2001, which shows a significant increase in the social welfare budget. A comparison with 2008 and 2011 shows a budget increase of 2.66 times. Figure 3 shows that the percentage of social welfare expenses that were distributed from the general expenditure increased 2.4 times between 2008 and 2011. Consequently, the social welfare budget significantly impacted the national budget and led the government to enforce a policy that the ID should strive to be financially independent by 2012.

\section{(hundreds of millions)}

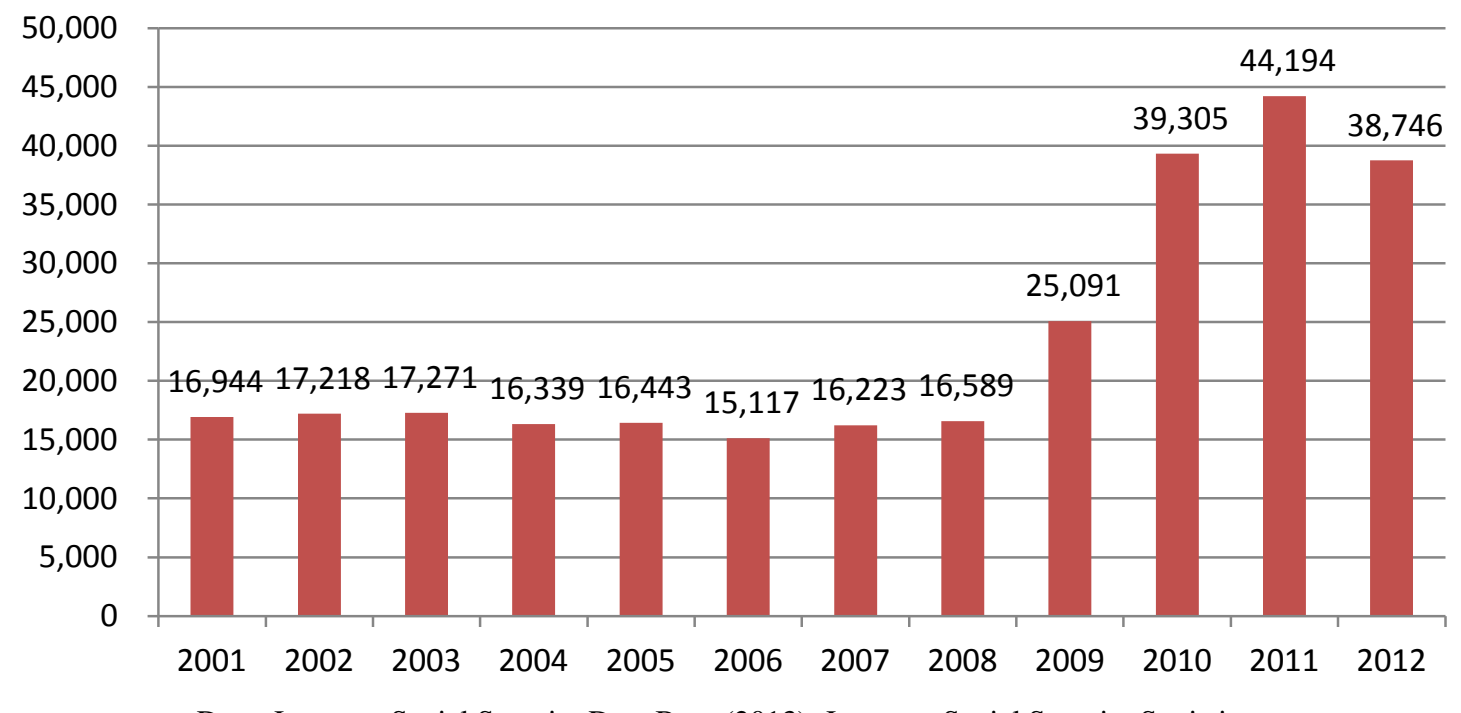

Data: Japanese Social Security Data Base (2013): Japanese Social Security Statistics

Figure 2: Trends In Social Welfare Expenses 


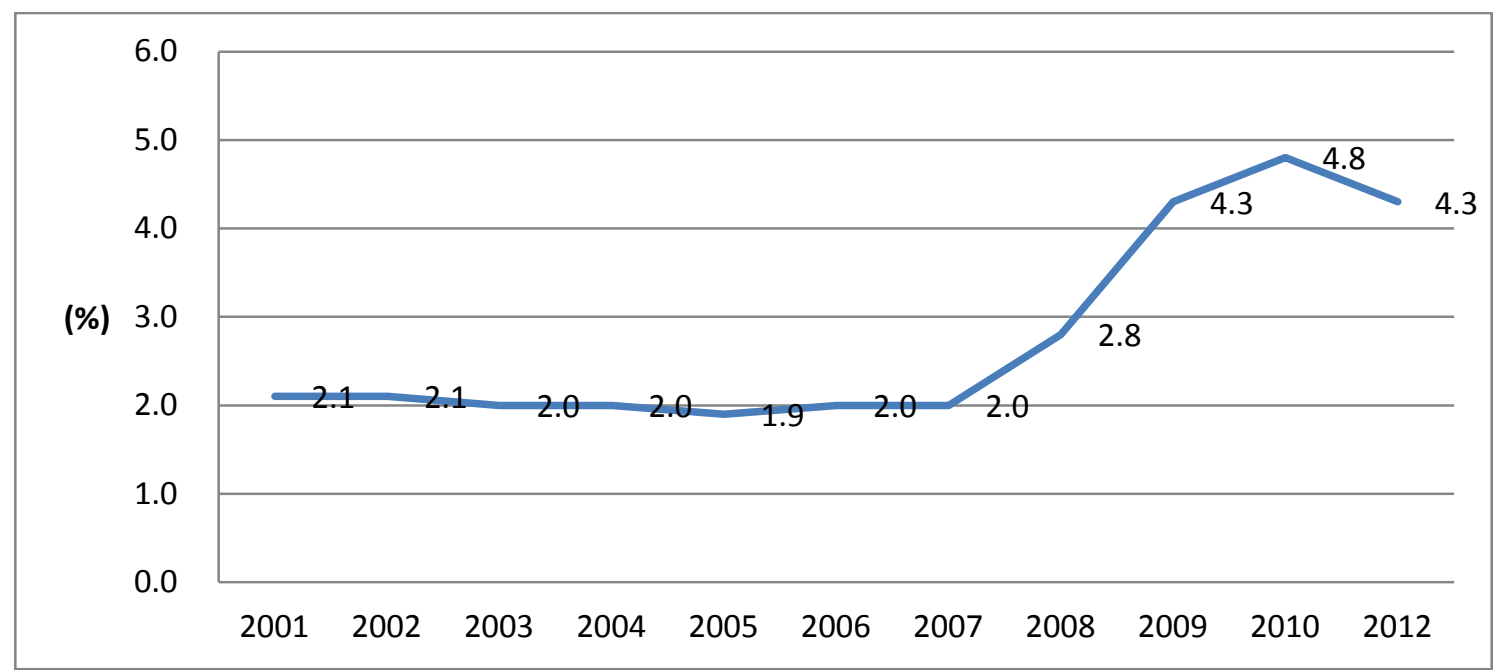

Data: Japanese Social Security Data Base (2013): Japanese Social Security Statistics

Figure 3: The Percentage Of Social Welfare Expenses Distributed From The General Expenditure

The new social welfare law is instituting change. First, it provides for vocational training to improve social abilities, and manner training and technical training that are termed transition support for employment. The training is designed to enable the ID to obtain work with companies or factories. The trainees must work while undergoing training for two years. Second, continued employment support assists those who cannot work in companies or factories because they lack sufficient social abilities, techniques, or cognitive capabilities. This service has two roles: the first is to provide vocational training programs and the second is to provide opportunities for paid work in the training facilities themselves. This service affects our organization in addition to others because the government ensures that the training facilities pay a minimum salary of 300 dollars a month to all workers. Therefore, social welfare organizations in Japan must find ways to produce income to pay ID workers. However, it is difficult to train the ID because they typically possess limited ability to understand, and lack communication skills.

\section{1-2. An Introduction To Our Organization And Facility}

Our organization is called "Social Welfare Organization Shouyuhkai". It is a welfare service provider in accordance with the social welfare law and is an alternative to Japanese government services. The organization was established in 1996 and has 294 employees. It is a type of nonprofit organization and the majority of income is from government sources. The organization manages nursing homes, provides housing support services, provides life care for each welfare type, and provides vocational training services for the handicapped, especially the ID. One organizational facility is called Yasuragi Yume Koubou, which translates to "peaceful dream maker" in English. It is a vocational training service provider for the ID. The change in laws made it necessary for the organization to explore ways to generate revenues that would provide for the ID.

Our organization first researched the characteristics of the ID to identify possible work within our organization including our nursing homes. Even after vocational training, the ID have difficulty finding employment in companies and factories. Our organization, therefore, decided to create jobs within the organization with the theory that, if management or support teams can understand the disabilities of the ID together with their strengths and weaknesses with respect to ability, we hypothesize that it can be possible for the ID to earn income.

\section{THE STUDY OF INTELLECTUAL DISABILITIES}

\section{2-1. The Characteristics Of The ID}

The term ID is a generic one and the specific disabilities include autism, learning disabilities, Asperger syndrome, and attention deficit hyperactivity disorder. Each disability has its own characteristics with accompanying positive and negative factors with respect to the ability to work. 
Individuals with Asperger syndrome have significant difficulties with social interaction and nonverbal communication (Klin, 2006). Therefore, conflict is a common problem because it is difficult for individuals with Asperger syndrome to understand the feelings of others and social situations. However, if an individual with Asperger syndrome is particularly interested in a topic, the individual has substantial powers of concentration and is keen to gather the relevant knowledge.

Individuals with autism can, in some cases, be unnecessarily punctilious and dissatisfied until a job is complete. For example, an autistic individual may be unable to stop washing dirty dishes until they are perfectly clean because the focus is on the dirt to the exclusion of all else. It is difficult for individuals with autism to adapt to many types of situations and self-mutilation is periodically a problem if the individual feels lost. Therefore, using the dish washing analogy, if the autistic individual is forced to stop washing dishes, he may become angry and confused (Klin, 2006).

Six positive characteristics of the ID were determined from an examination:

1. Orderliness or punctiliousness.

2. A desire to follow the same pattern.

3. To be punctilious beyond necessity and to be unsatisfied until a job is complete.

4. High IQ levels but difficulty communicating.

5. A lack of concern for others.

6. Mid-levels of IQ but an inability to listen, read, or write.

\section{2-2. Study Of The ID Work Condition}

The study of the characteristics of the ID revealed that the ID prefer certain conditions. Improving the environmental conditions for the ID to make them comfortable requires the development of easy to follow rules. Rules facilitate the need for the ID to follow similar patterns and to repeat the same pattern many times. Autistic individuals especially require a clear end-point or a quantity to complete that will signal the end of a task. Change can be problematic. A schedule or timetable can be adhered to; however, changes will result in mental instability. Additionally, non-verbal communication is preferable, especially visual communication that uses pictures. Examples of suitable ways to communicate with the ID and to improve working conditions for the ID are the following:

1. Create and use patterns.

2. Use color to discern specific items.

3. Use pictures to describe what to do.

4. Use products that are straightforward and easy to use.

5. Develop easy to follow rules.

6. Create a timetable or schedule.

7. Clearly describe where not to go.

8. Clearly describe where things belong.

(American Association on Intellectual and Developmental Disabilities, 2010), (Masami Sasaki, (2004), (University of North Carolina School of Medicine "Teach autism program"

Retrieved from http://teacch.com/)

\section{2-3. Creating Work In Our Organization}

Our study concerning ID characteristics and preferred conditions suggested that suitable tasks for the ID include cooking, linen change, cleaning, and tasks associated with a role as a worker's aid. However, all tasks require an environment conducive to the preferences and easy to follow rules and instructions required by the ID.

Initially, our organization focused on the task of linen change in nursing homes. Patterns that describe the linen change process were easy to create and it was possible to conduct linen change with a team of two people, of whom one was disabled and the other was not. First, a trainer created a manual explaining the linen change process 
using pictures, and the practice was repeated many times. The crucial factor is that the process should not be complicated. The task of linen change is beneficial to both the ID and the nursing homes, because the professional care staff that used to change the linen are no longer required and salary costs are reduced. Gradually, the ID workers memorized the pattern and are now able to complete the task independently. However, if the unexpected occurs they are problem. Therefore, a manager who is not disabled is required to control and manage the work. Consequently, the ID workers are able to change the linen effectively and receive 300 dollars per hour in compensation.

The next challenge was cleaning the individual nursing home rooms. Cleaning is a desirable job for the ID who are concerned with cleanliness. The ID were already changing the linen, therefore, we considered that while changing the linen, cleaning the rooms at the same time might be advantageous because the manager can observe both the linen change and the cleaning simultaneously saving the cost of additional labor for another trainer. The cleaning task is also beneficial for the nursing homes although quality control is an issue. Cleaning is a complex task, especially the identification of dirty areas and choosing the right equipment and products to use. A manual was developed and multi-use cleaning products were provided. The result is high-quality cleaning.

The third challenge was cooking and delivering lunch to the handicapped and elderly who live in the nursing or care homes that are managed by our organization. Some of our nursing homes had been outsourcing the cooking operations for the elderly. This amounts to the preparation and service of food three times a day. Each nursing home was spending approximately 200,000 to 350,000 dollars for outsourced cooking services and the total cost was more than one million dollars. Therefore, if the ID could work in the kitchen or provide food instead of outsourcing the task, that would be a better option. However, we also believed that it was necessary to prepare the kitchen for ease of use and to limit the need to move from one location to another.

At that time, the government provided us with the opportunity to build a new training facility. We therefore planned the layout of the building and added a kitchen facility that was considered easy to use and adaptable to the patterns that the ID worker requires. This facility opened in 2012, and 20 ID currently prepare food and deliver hundreds of daily lunches to other handicapped facilities. The success of the food preparation lies in the patterns used in recipes, menus, and the food preparation. Income is now approximately 13,000 dollars per month. The profit exceeds 7,000 dollars, which means that the each ID receive an average salary of 350 dollars per month. This amount is more than 10 times the amount required by government standards. The work benefits the ID people because customer numbers are stable and, if the ID workers want to increase their earnings, the organization can provide service to additional handicapped people. Our organization benefits because we receive funds for training the ID workers and caring for the handicapped people. The program is of mutual benefit to the ID and to our organization within the social welfare society.

The final challenge was the role of worker's aide, which is similar to the role of teacher's aide. Routine administrative tasks in our organization include typing, work with computers, printing, creating business cards and envelopes, and copying. Currently, the minimum salary per hour is set by the government, which is eight dollars and fifty cents. However, it is difficult to hire workers at this rate and the average wage is closer to nine dollars and fifty cents. It is preferable, therefore, that we control the real salary that is dependent on the level of the abilities of the individual ID workers. Both our organization and the ID workers are satisfied with the policy.

\section{THE RESULT OF THE CHALLENGES OF ID WORKERS}

The results of the four work types that are undertaken by the ID demonstrate a successful business model. The model has succeeded in avoiding the high salary costs imposed by government and in securing double income for the organization by assisting the ID and the handicapped and by cutting salary costs.

Moreover, intangible results in the form of motivated ID workers have led to increased confidence in the ID who have historically been considered to be of limited use to society and not a valuable part of the labor force. The ID demonstrate a desire to work given the appropriate opportunity. Additionally, the ID workers experience improved quality of life from acquiring new skills such as the ability to cook, clean and use computers. 


\section{CONCLUSION}

The new business model was constructed by examining possible methods to expand the working roles for the ID. The business model acquires double income for our organization by training ID workers and caring for the handicapped people for the government. The model is mutually beneficial for the ID people and our organization within the social welfare society. Additionally, the model contributes to the national economy because it has succeeded in identifying ways in which the ID worker can earn income that is ten times the amount necessary to obtain independence at a level that reduces social welfare expense. The challenges faced by the ID worker provide motivation for work and for the acquisition of skills that lead to a better quality of life. Therefore, this new business model is beneficial for business and the education of the ID.

\section{AUTHOR INFORMATOIN}

Haruyo Wada MBA, MAL, is a board of member for Social Welfare Organization Shouyuhkai. She has fifteen years of experience of planning social welfare business in nonprofit organization. Her research interests are in the areas of expanding the social welfare business, of education for handicapped and of education for care givers.

E-mail: haruyo.wada@ shouyuhkai.jp

Kenji Ishikawa is fifteen years of experience of a professional certificated care giver in Social Welfare Organization Shouyuhkai. His research interest is creating cleaning works for intellectually disabled people.

E-mail: kenji.ishikawa@ shouyuhkai.jp

Mitsuharu Ohta is a professional certificated nutritionist in Social Welfare Organization Shouyuhkai. His research interest is to create menu and tasks for intellectually disabled people. E-mail: mitsuharu.ohta@ shouyuhkai.jp

Miwa Kojima is a professional consultant in Social Welfare Organization Shouyuhkai. Her research interests are consultation for handicapped and planning the total support services for intellectually disabled people.E-mail: miwa.kojima@shouyuhkai.jp

Motoki Saito is a professional care giver in Social Welfare Organization Shouyuhkai. His research interests are the method of caring heavy level of intellectually disabled people and education for the care givers. E-mail: motoki.saito@shouyuhkai.jp

Kanako Baba is a professional trainer of job tasks for intellectually disabled people in Social Welfare Organization Shouyuhkai. Her research interests are creating job tasks and method of training for handicapped. E-mail: kanako.baba@ shouyuhkai.jp

Hiroko Mikame is a professional trainer of job tasks for intellectually disabled people in Social Welfare Organization Shouyuhkai. Her research interests are TEACCH program and method of teaching for intellectually disabled people. E-mail: hiroko.mikame@ @ shouyuhkai.jp

\section{REFERENCES}

1. American Association on Intellectual and Developmental Disabilities (2010) "Intellectual disabilities"

2. Ami Klin (2006) "Autism and Asperger syndrome: an overview, Revista Brasileira de Psiquiatria, vol.28.

3. Japanese Social Security Data Base (2013) "Japanese Social Security Statistics Database"

4. Masami Sasaki (2004) "Structure seen with the picture for autism"

5. Ministry of Education, Sports, Science, and Technology, Japan (2013) "Education for learning difficulties"

6. Ministry of Health, Labor, and Welfare (2005) "Survey on person with intellectual disability"

7. Ministry of Health, Labor, and Welfare (2012) "The ID people statistics"

8. University of North Carolina School of Medicine "Teach autism program"

9. Retrieved from http://teacch.com/ 